\title{
SURVEI PERKEMBANGAN PEMBINAAN CABANG OLAHRAGA SEPAK BOLA TIM PS PADU KECAMATAN BONGOMEME KABUPATEN GORONTALO
}

\section{SURVEY FOR THE DEVELOPMENT OF SOCCER BRANCHES PS PADU TEAM, BONGOMEME DISTRICT GORONTALO DISTRICT}

\author{
Risna Podungge, Abdul Wahab A. S. Amura \\ Jurusan Pendidikan Jasmani, Kesehatan dan Rekreasi, Fakultas Olahraga dan Kesehatan, \\ Universitas Negeri Gorontalo \\ Kontak penulis: risnapodungge@yahoo.co.id.
}

\begin{abstract}
ABSTRAK
Tujuan dari penelitian ini yaitu untuk mensurvei perkembangan pembinaan cabang olahraga sepak bola tim PS Padu, Kecamatan Bongomeme, Kabupaten Gorontalo. Penelitian ini merupakan penelitian kualitatif dengan metode observasi, wawancara, dokumentasi, kemudian keabsahan data menggunakan triangulasi atau gabungan. Objek penelitian ini menggunakan responden penelitian yaitu pelatih, pemain, tokoh masyarakat, tokoh adat, dan pemerintah setempat.
\end{abstract}

Kata Kunci: survei; pembinaan sepak bola

\begin{abstract}
The purpose of this study was to survey the development of the PS Padu team soccer coaching, Bongomeme District, Gorontalo Regency. This research is a qualitative research with the method of observation, interviews, documentation, then the validity of the data using triangulation or a combination. The object of this study used research respondents, namely coaches, players, community leaders, traditional leaders, and local government.
\end{abstract}

Keywords: survey; football coaching 


\section{Pendahuluan}

Perkembangan sepak bola di Kabupaten Gorontalo khususnya di Kecamatan Bongomeme sudah ada sejak pada tahun 1973, masyarakat dan para pemain mulai memikirkan hal yang baru yakni dengan mendirikan sebuah club karena dengan adanya peningkatan jumlah peminat cabang olahraga sepak bola. Hal ini di karenakan dari kedua Desa yakni Desa Pangada'a dan Desa Dulamayo lebih banyak menyumbangkan pemain sehingganya mereka menamakan tim Ps Padu di dalamnya merupakan para pemain yang di perpadukan dari Desa Pangada'a dan Desa Dulamayo. Pada dasarnya, peran pemerintah dalam sektor olahraga terutama sepak bola mulai dperhatikan pada masa orde lama (Aji, 2016).

Berkembang atau tidaknya olahraga sepak bola tergantung bagaiman sepak bola menjadi sumber keuntungan (Haryadi et al., 2017). Pembinaan olahragawan sedini mungkin melalui pencarian dan pemantauan bakat, pembibitan, pendidikan dan pelatihan olahraga prestasi yang didasarkan pada ilmu pengetahuan dan teknologi secara lebih efektif serta peningkatan kualitas organisasi olahraga baik tingkat pusat maupun daerah (Nugraha et al., 2019) khusunya tim Ps Padu tergantung penerapan menejemen organsasi untuk pembinaan di suatu club, dalam usaha pembinaan prestasi olahraga sepakbola, diperlukan unsur pendukung yang sangat vital. Salah satu unsur tersebut adalah pelatih yang berpendidikan (Dio, 2018).

Pelatih yang berpendidikan adalah pelatih yang memahami dengan baik masalahmasalah yang menyangkut kepelatihan, sebuah klub akan mempunyai peluang yang jauh lebih besar untuk berhasil dan berprestasi dari pada klub yang tidak menggunakan pelatih yang tidak mempunyai dasar dalam ilmu kepelatihan (Jamalong, 2014) (Mylsidayu \& Kurniawan, 2015) (Nurkadri, 2017). Pelatihan yang di berikan pada setiap pemain lebih mengarah kedalam proses kedisiplinan, itu merupakan hal yang utama dalam proses pembinaan para pemain tim Ps Padu.

Pembinaan cabang olahraga sepak bola yang sekarang ini lebih di perhatikan oleh pihak pemerintah hal ini di buktikan dengan program 4 tahunan yang akan di laksanakan oleh pihak pemerintah yakni memaksimalkan SSB (Sekolah Sepak Bola) (Handoko et al., 2019), ini disampaikan oleh Bapak Aswad Dako A.Md selaku Kepala desa dulamayo dan sekaligus ketua koni Kecamatan Bongomeme yang rencanya akan memulai tahap awal pada bulan Desember mendatang. Banyaknya dukungan yang datang dari pihak pemerintah dan para pengurus menejemen serta dukungan yang datang dari pihak masyarakat dan terlebih khusus dari orang tua para pemain, ini memberikan hal yang postif bagi tim Ps Padu, perkembangan para pemain mulai muncul, selain itu sarana dan prasarana sudah mulai lebih baik dari pada yang sebelumnya. Para pemain juga sudah mulai lagi bersemangat dalam melaksanakan latihan yang setiap rutin dalam seminggu di lakukan sebanyak 3 hingga 4 kali pertemuan dan itu membawa hasil yang positif bagi para pemain Ps Padu yang ada di Kecamatan Bongomeme.

Perkembangan pembinaan sepak bola tim Ps Padu di Kecamatan Bongomeme sudah ada, ini dibuktikan dengan lahirnya bibit-bibit para pemain, dan adanya pemain Ps Padu yang sudah di cabut langsung oleh official Persidago yang sampai sekarang ini sudah rutin berlatih dengan tim Persidago. Adapun nama-nama yang sekarang ini sudah terkaper dalam tim persidago antara lain Fahril Makoya, Riski Malipi, Wawan Jafar, Aripin Gubali. Disisi lain 
perkembangan sarana dan prasarana sudah ada terutama pada pembinaan cabang olahraga sepak bola yang dulunya masih tidak tertata dengan dengan baik dan adanya dukungan dari luar yakni dari pihak pemerintah dan masyarakat yang mendukung serta mensuport penuh.

\section{Metode}

Penelitian ini merupakan penelitian kualitatif yang dilakukan di Kecamatan Bongomeme, Kabupaten Gorontalo, Provinsi Gorontalo dengan responden penelitian yaitu pelatih, pemain, tokoh masyarakat, tokoh adat, dan pemerintah setempat. Instrumen pengumpulan data menggunakan teknik observasi, wawancara, dokumentasi, kemudian keabsahan data menggunakan triangulasi atau gabungan.

\section{Hasil}

\section{Deskripsi Hasil Penelitian}

Hasil penelitian yang berjudul "Survei Perkembangan Pembinaan Cabang Olahraga Sepak Bola Pada Tim Ps Padu di Kecamatan Bongomeme Kabupaten Gorontalo" dilaksanakan selama waktu yang dibutuhkan. Tahap awal penelitian dilakukan secara umum. Peneliti mengumpulkan data dan informasi sebanyak mungkin yang berkaitan dengan olahraga sepak bola. Penelitian ini dilakukan secara lisan yang berupa wawancara dengan 5 responden, pertama mewawancarai Bapak Aswad Dako, A.Md selaku pemertintah kepala Desa Dulamayo Kecamatan Bongomeme, Bapak Rahim Yusuf selaku tokoh adat, Aripin Gubali selaku Pemain Ps Padu, Haris Malik selaku Pelatih sepak bola tim Ps Padu, Irwan Samuda selaku tokoh masyarakat.

\section{Olahraga Sepak Bola}

Menurut Bapak Rahim Yusuf selaku tokoh adat mengatakan bahwa sepak bola masuk di Kecamatan Bongomeme Kabupaten Gorontalo tidak diketahui pasti kapan masuknya hanya saja pada tahun 1970 sudah ada dan mulai dimainkan. Sementara menurut Bapak Aswad Dako, A.Md selaku kepala Desa Dulamayo mengemukakan olahraga sepak bola masuk di Kecamatan Bongomeme pada tahun 1980-an. Dan menurut beliau juga sepak bola adalah olahraga merakyat yang dimainkan secara individu dan kelompok dengan menggunakan semua anggota tubuh yang lebih khusus adalah menggunakan kaki dan juga memerlukan lapangan yang luas dan mempunyai gawang sebagai tempat untuk memasukan bola. Permainan ini di mainkan oleh dua tim dan tiap tim terdiri dari 11 orang pemain yang masing-masing mempunyai posisi tersendiri.salah satu tim atau regu dinyatakan menang jika berhasil memasukan bola ke dalam gawang tim lawan.

\section{Perkembangan}

Dari hasil penelitian yang dilakukan oleh peneliti di Kecamatan Bongomeme Kabupaten Gorontalo sepak bola memiliki perkembangan yang tingkat peminat yang cukup besar, di Kecamatan Bongomeme peneliti menemukan ada beberapa lapangan yang diisi oleh setiap pemain, akan tetapi lapangan memiliki jumlah pemain yang melebihi jumlah pemain sepak bola itu sendiri ada di desa Dulamayo tempat latihan Ps Padu. Sekian banyaknya jumlah peminat olahraga sepak bola membuat para pemain harus bergantian untuk bermain dilapangan. 
Terjadinya peningkatan pemain di karenakan para pemain dari desa lain yang ikut serta dalam permainan. Dari peningkatan pemaian yang ada sehinggnya masyarakat setempat memberikan saran untuk mendirikan sebuah tim degan mengabungkan kedua Desa, karena dari kedua Desa ini lebih banyak menyumbangkan pemain seinggnya mereka menamakan tim Ps Padu. Jadi awalnya tim Ps Padu(Pangada'a,Dulamayo) berdiri karena ada kesepakatan dari pihak luar dan dari para pemain serta dukungan dari pemerintah setempat meskipun sarana dan prasarana yang ada belum cukup memadai.

Dari segi sarana dan prasarana peneliti melihat lapangan yang digunakan oleh para pemain sudah termasuk standar seperti lapangan sepak bola yang digunakan pada umumnya. Standar yang dimaksud disini adalah lapangan yang sudah bisa digunakan dalam pertandingan.

Bapak Aswat Dako,A.Md juga mengatakan rencananya kedepan akan memperkenakan tim sepak bola Ps Padu di Kecamatan Bongomeme keajang kompotisi yang bergengsi. Olahraga sepak bola khususnya tim Ps Padu di Kecamatan Bongomeme harus dikembangkan guna untuk mendapatkan prestasi demi mengangkat nama baik kecamatan dan terlebih khusus untuk para pemain. Dan pihak pemerintah juga sedang dalam persiapan 4 tahun regenerasi demi memaksimalkan SBB di bawah naungan menejemen yang ada sekarang.

\section{Hambatan}

Pelatih Ps Padu Haris Malik juga mengatakan bahwa hambatan tim Ps Padu yang dikelolahnya selain saran dan prasarana juga sangat terkendala dalam hal pendanaan club. Pendanaan yang kurang di perhatikan oleh pihak pemerintah setempat ini dapat mempengaruhi prestasi yang akan dicapai oleh tim dan menejemen yang masih timpang siur yang belum di ketahui pasti ke mana arah dan tujuan menejemen persepak bolaan khususnya tim Ps Padu. Akan tetapi seiring dengan berjalannya waktu, dukungan dari pemerintah sudah ada dan mampu memberikan dukungan terkait dengan lebih memperhatikan sarana dan prasaran yang masih kurang.

\section{Responden}

Setiap cabang olahraga pasti sangat membutuhkan perhatian khusus dari pihak pemerintah, yang menabur harapan lebih agar olahraga yang ada di Kecamatan Bongomeme itu sendiri akan berkembang dari yang sebelumnya. Mencangkup hasil analisis peneliitan bahwa pemerintah disini merupakan wadah utama untuk terlaksankannya kegiatan olahraga sepak bola, peran pemerintah dalam partisipasi olahraga sepak bola khususnya tim Ps Padu sangat dibutuhkan club itu sendiri, guna dalam mengembangkan/melestarikan sepak bola yang ada di Kecamatan Bongomeme.

Adapun penuturan Bapak Irwan Samuda selaku tokoh masyarakat Kecamatan Bongomeme terkait dengan olahraga sepak bola terutama dengan adanya tim Ps Padu ini memberikan hasil yang positif bagi masyarakat setempat, terbukti dengan adanya dukungandukungan dari setiap warga masyarakat dan bukan hanya dari masyarakat kaula muda melainkan juga dengan kaula tua yang ikut serta dalam mendukung olahraga sepak bola khususnya tim Ps Padu yang ada di Kecamatan Bongomeme. Beliau juga mengatakan ketika tim Ps Padu melakukan pertandingan atau uji coba dengan tim yang dari luar Kecamatan Bongomeme, 
masyarakat setempat sangat mengantusias untuk mensuport atau mendukung penuh tim Ps Padu meskipun dengan sarana dan prasarana yang belum cukup memadai, dan menejemen club yang masih tidak di ketahui pasti tujuan utama dari struktur organisasi, hal ini tidak menjadi sebuah alasan untuk tidak mendukung sepak yang ada di Kecamatan Bongomeme khususnya tim Ps Padu. Beliau juga memberikan harapan lebih dengan adanya tim Ps padu ini mampu membawa tim sepak bola yang ada di Kecamatan Bongomeme bisa kejenjang yang lebih tinggi.

Pendapat yang lain juga datang dari bapak Haris Malik sebagai pelatih Ps Padu mengatakan bahwa perkembangan olahraga sepak bola pada tim sangat baik dan tim ini dibentuk pada tahun 1973. Ini di buktkan hasil pretasi yang di raih pada tahun 1975 yang menjuarai rayon Batudaa akan tetapi pada saat itu tim Ps padu belum tertata dan terakomodir dengan baik, pada tahun 1980-an tim Ps Padu sudah mulai rutin ikut dalam pertandingan sepak bola. dengan hadirnya olahraga sepak bola ini selain kegiatan keseharian juga mempunyai manfaat lainya seperti menyehatkan anggota tubuh jasmani maupun rohani.

Permainan sepak bola juga mengadung nilai-nilai sosial. Dan proses pembinaan para pemain Ps Padu lebih difokuskan pada tahap pembentukan mental di setiap individu,dari waktu latihan yang di berikan pada tin Ps Padu dalam seminggu 3 hingga 4 kali latihan. Dalam proses pembinaan lain yang di berikan lebih mengarah pada kedisiplianan, dari proses pembinaan cabang olahraga sepak bola yang di terapkan di tim Ps Padu melahirkan bibit-bibit para pemain sehingga ada beberapa para pemain yang di panggil langsung oleh official Persidago dan langsung ikut latihan bersama tim Persidago, adapun nama-nama yang di panggil oleh official Persidago adalah Fahril Makoya, Riski Malipi, Wawan Jafar, Aripin Gubali.

Haris Malik mengatakan apabila pemain di dapat hanya menggunakan kaus oblong sekalipun menggunakan sepatu beliau tidak akan memasukan pemain tersebut dalam latihan. Sementara disisi lain semangat yang ada di seluruh pemain tim Ps Padu harus di apresiasi karena dilihat segi sarana dan prasarana yang ada belum cukup memadai mereka tetap sangat bersamangat. Beliau juga sebagai pelatih utama tim Ps Padu sangat berharap pemerintah setempat agar bisa mendukung penuh cabang olahraga yang ada di Kecamatan Bongomeme khususnya dengan adanya tim Ps Padu agar bisa berkembang dan dapat membawa hasil yang positif bagi Kecamatan Bongomeme. Adapun Tujuan dari pihak pelatih dengan dibentuknya tim Ps Padu agar dapat membawa prestasi.

Menurut Aripin Gubali selaku pemain tim Ps Padu olahraga sepak bola ini adalah olahraga yang merakyat, hampir di seluruh desa maupun kecamatan mengetahui olahraga tersebut, dan yang menjadi faktor utama yang mendorong beliau untuk ikut bergabung dengan tim Ps Padu yakni selain hobi dan juga ingin membawa prestasi bagi individu maupun secara tim, dan juga saling bersaing memperlihatkan kemampuan yang di miliki. Akan tetapi beliau juga menuturkan bahwa tim Ps Padu ini mempunyai hambatan dalam sarana dan prasaran, tetapi hal ini tidak menghilangkan semangat beliau untuk tetap berkarir dalam sepak bola. Tetapi dengan adanya menejemen yang sudah memperhatikan club, sarana dan prasaran sudah mulai memadai dari saranan dan prasarana yang sebelumnya.

\section{Faktor Pendukung}


Faktor pendukung mempunyai peran penting disetiap cabang olahraga. Dilihat dari faktor pendukung yang ada dari cabang olahraga sepak bola faktor yang paling utama yakni meliputi faktor dalam segi pendanaan. Pendanaan sangat diperlukan dalam cabang olahraga terutama cabang olahraga sepak bola.

\section{Pendanaan}

Penuturan Bapak Haris Malik selaku pelatih tim Ps Padu Mengatakan bahwa sumber dana untuk pencapaian terselenggaranya olahraga sepak bola dan terbentuknya tim Ps Padu berasal dari swadaya masyarakat dan para offsial tim sedangakan para pemain tidak di bebankan, pemain hanya fokus pada pertadingan yang akan di mainkan nanti. Masyarakat dan para offisial bekerja sama dalam hal pengadaan dana, ini dilakukan sebagai faktor utama untuk menunjang sarana dan prasarana yang masih kurang dalam tim Ps Padu.

Menurut salah seorang warga masyarakat setempat, masyarakat tidak merasa keberatan dengan dimintai iuran akan tetapi masyarakat sangat antusias dan mendukung penuh cabang olahraga sepak bola khususnya tim Ps Padu demi untuk mengembangkan olahraga sepak bola pada tim Ps Padu yang ada di Kecamatan Bongomeme Kabupaten Gorontalo.

\section{Sarana dan Prasarana}

Sarana dan prasarana olahraga sepak bola yang ada pada tim Ps Padu di Kecamatan Bongomeme yang sudah cukup memadai, ini menjadi salah satu upaya pemertintah dan para menejemen club untuk lebih meningkatan semangat para pemain ataupun para peminatnya itu sendri. Sarana dan prasarana sendiri merupakan faktor pendukung yang harus dijalankan secara efektif dalam menjalankan manajemen dalam sepak bola (Dadi Dartija, 2013).

Oleh karena itu cabang olahraga sepak bola tetap menjadi unggulan apalagi dengan adanya tim Ps Pada yang di harapkan akan mampu memberikan hasil yang positif bagi Kecamatan Bongomeme. Dan olahraga sepak bola sudah menjadi olahraga unggulan sehingga potensi yang dimiliki oleh para pemain tim Ps Padu menjadikan olahraga sepak bola sebagai wadah untuk mengembangkan bakat (Prawira \& Tribinuka, 2016).

Berdasarkan hasil wawancara dengan Bapak Haris Malik menyampaikan terkait dengan sarana dan prasarana yang ada pada tim Ps Padu masih kurang memadai. Yang menjadi faktor utama terkendalanya dalam menunjang perkembangan tim Ps Padu adalah sarana dan prasaran, ini merupakan faktor yang sangat penting dalam sebuah tim dan juga salah satu unsur utama demi mengembangkan tim Ps Padu di Kecamatan Bongomeme. akan tetapi pihak dan pemerintah sudah berusaha yang terbaik untuk meningkatkan sarana dan prasarana hal ini dibuktikan dengan adanya perehapan lapangan Ps Padu.

\section{Pembahasan}

Adapun hasil penelitian yang telah diperoleh terkait dengan perkembangan pembinaan cabang olahraga sepak bola pada tim Ps Padu di Kecamatan Bongomeme, dimana tim Ps Padu di Kecamatan Bongomeme sudah ada perkembangan karena hal didukung oleh pihak pemerintah dan mendapatkan respon yang positif dari pihak masyarakat setempat, di tambah lagi sarana dan prasarana yang sudah memadai sehingga menambah semangat para pemain untuk mengasah 
potensi yang mereka miliki. Faktor pendukung pembinaan cabang olahraga sepak bola pada tim Ps Padu yang ada di Kecamatan Bongomeme, karena adanya dukungan dari masyarakat dan kemauan dari para pemain tersendri untuk mengembangkan tim Ps Padu sehingga dapat membawa prestasi di tingkat Kecamatan maupun sampai di tingkat Kabupaten dan mampu mengasilkan pemain yang berkualitas.

Dukungan dari berbagai pihan dapat memotivasi pemain untuk dapat memperoleh prestasi yang maskimal (Bruno, 2017) (Hadjarati \& Haryanto, 2020). Selain itu, peran dari pelatih juga dapat menambah potensi untuk berprestasi dalam sepak bola (Ruslan \& Sangadji, 2021). Maka untuk aspek dukungan tersebut haruslah dilakukan dengan sepenuh hati, sebagai tambahan dalam pengoptimalan prestasi.

Selain faktor pendukung terdapat juga faktor pengahambat yakni diantaranya sarana dan prasaran yang belum semuanya fasilitas memadai akan tetapi dengan adanya menejemen olaharaga sudah meminimalisir sarana dan prasarana yang masih kurang memadai pada tim Ps Padu.

\section{Kesimpulan}

Berdasarkan penelitian tentang perkembangan pembinaan cabang olahraga sepak bola pada tim Ps Padu di Kecamatan Bongomeme Kabupaten Gorontalo dapat disimpulkan bahwa dengan adanya tim Ps Padu memiliki perkembangan dari segi peminatnya maupun pada tim itu sendiri. Hal ini dilihat dari segi apresiasi masyarakat dan para pemerintah setempat yang mendukung penuh demi perkembangannya tim Ps Padu, dari segi sarana dan prasarana sudah mulai memadai dan ini menjadi salah satu faktor berkembanganya potensi dan bakat serta prestasi para pemain tim Ps Padu yang ada di Kecamatan Bongomeme.

\section{Referensi}

Aji, R. B. (2016). Sepak Bola dan Eksistensi Bangsa Dalam Olimpiade Masa Orde Lama (19451966). MOZAIK HUMANIORA.

Bruno, L. (2017). Hubungan Dukungan Orang Tua Siswa Dengan Motivasi Siswa Dalam Mengikuti Sekolah Sepak Bola (Ssb. Jurnal Ilmiah FKIP Universitas Subang.

Dadi Dartija. (2013). Pendataan, Pemetaan Sarana Dan Prasarana Olahraga Pendidikan Di Kabupaten Aceh Selatan Dari Tahun 2002 Sampai Dengan 2012. Visipena Journal. https://doi.org/10.46244/visipena.v4i1.115

Dio, R. (2018). Gaya Kepemimpinan Pelatih Dalam Penerapan Sistem Pengendalian Manajemen Dalam Klub Bintang Timur Surabaya. Jurnal Ilmiah Mahasiswa Universitas Surabaya.

Hadjarati, H., \& Haryanto, A. I. (2020). Motivasi Untuk Hasil Pembelajaran Senam Lantai. Multilateral Jurnal Pendidikan Jasmani Dan Olahraga. https://doi.org/10.20527/multilateral.v19i2.8646

Handoko, J., Sugihartono, T., \& Sutisyana, A. (2019). Analisis Program Latihan Sepak Bola Grass Root Dan Implementasinya Pada Sekolah Sepak Bola (SSB) Kabupaten Kepahiang. KINESTETIK. https://doi.org/10.33369/jk.v3i2.8995

Haryadi, W. M., Pratidina, G., \& Seran, M. Y. (2017). Studi Manajemen Pembinaan Olahraga Sepak Bola Di Klub Persatuan Sepak Bola Kota Bogor Oleh Kantor Pemuda Dan Olahraga Kota Bogor. JURNAL GOVERNANSI. https://doi.org/10.30997/jgs.v2i1.208

Jamalong, A. (2014). Peningkatan Prestasi Olahraga Nasional Secara Dini Melalui Pusat Pembinaan Dan Latihan Pelajar (PPLP) Dan Pusat Pembinaan Dan Latihan Mahasiswa (PPLM). Jurnal Pendidikan Olahraga. 
Mylsidayu, A., \& Kurniawan, F. (2015). Ilmu kepelatihan dasar. Bandung: Alfabeta.

Nugraha, U., Mardian, R., \& Hardinata, R. (2019). Evaluasi Program Manajemen Klub Sepakbola Kota Jambi. Cerdas Sifa.

Nurkadri, N. (2017). Perencanaan Latihan. JURNAL PRESTASI. https://doi.org/10.24114/jp.v1i2.8059

Prawira, R. R. Z., \& Tribinuka, T. (2016). Pembinaan Pemain Muda Melalui Akademi Sepak Bola. Jurnal Sains Dan Seni ITS.

Ruslan, R., \& Sangadji, F. (2021). Zig-Zag Running Exercises For Ball Drill Skills. Jambura Journal of Sports Coaching, 3(1). 